\title{
SOME NEW GENERALIZED FORMS OF HARDY'S TYPE INEQUALITY ON TIME SCALES
}

\author{
S. H. Saker, R. R. Mahmoud, M. M. Osman and R. P. Agarwal
}

Abstract. In this paper, we prove some new dynamic inequalities from which some known dynamic inequalities on time scales, some integral and discrete inequalities due to Hardy, Copson, Chow, Levinson, Pachpatte Yang and Hwang will be deduced as special cases. Also, some new corresponding integral and discrete inequalities will be formulated. The results will be proved by employing the chain rule, integration by parts formula, Hölder's inequality and Jensen's inequality on time scales.

Mathematics subject classification (2010): 26A15, 26D10, 26D15, 39A13, 34A40, 34N05.

Keywords and phrases: Hardy's inequality, Copson's inequality, time scales.

\section{REFERENCES}

[1] R. P. Agarwal, M. Bohner And S. H. Saker, Dynamic Littlewood-type inequalities, Proceedings of the American Mathematical Society 143 (2015), 667-677.

[2] R. P. Agarwal, D. O’Regan and S. H. Saker, Dynamic Inequalities on Time Scales, Springer, Cham, (2014).

[3] G. Bennett, Some elementary inequalities, The Quarterly Journal of Mathematics Oxford 38 (2) (1987), 401-425.

[4] P. R. BEESACK, Hardy's inequality and its extensions, Pacific Journal of Mathematics 11 (1) (1961), 39-61.

[5] M. Bohner And A. Peterson, Dynamic Equations on Time Scales: An Introduction with Applications, Birkhäuser, Boston, (2001).

[6] E. T. Copson, Note on series of positive terms, Journal of the London Mathematical Society 2 (1927), $9-12$.

[7] E. T. Copson, Note on series of positive terms, Journal of the London Mathematical Society 3 (1928), 49-51.

[8] E. T. Copson, Some integral inequalities, Proceedings of the Royal Society of Edinburgh 75A (13) (1976), 157-164.

[9] E. B. ElliotT, A simple exposition of some recently proved facts as to convergency, Journal of the London Mathematical Society 1 (1926), 93-96.

[10] G. H. HARDY, Note on a theorem of Hilbert, Mathematische Zeitschrift 6 (1920), 314-317.

[11] G. H. HARDY, Notes on some points in the integral calculus (LX): An inequality between integrals, Messenger of Mathematics 54 (1925), 150-156.

[12] G. H. HARDY, Notes on some points in the integral calculus (LXIV), Messenger of Mathematics 57 (1928), 12-16.

[13] G. H. HARdy AND J. E. LitTlewood, Elementary theorems concerning power series with positive coefficients and moment constants of positive functions, Journal für die reine und angewandte Mathematik 157 (1927), 141-158.

[14] G. H. Hardy, J. E. Littlewood and G. Polya, Inequalities, second edition, Cambridge University Press, Cambridge (1952).

[15] A. Kufner And L.-E. Persson, Weighted Inequalities of Hardy Type, World Scientific Publishing Co., Singapore, New Jersy, London, Hong Kong (2003). 
[16] A. Kufner, L. Maligranda And L.-E. Persson, The Hardy Inequalities: About its History and Some Related Results, Vydavatelski Servis Publishing House, Pilsen (2007).

[17] L. LeINDLER, Generalization of inequalities of Hardy and Littlewood, Acta Scientiarum Mathematicarum (Szeged) 31 (1970), 297-285.

[18] N. LEvinson, Generalization of an inequality of Hardy, Duke Mathematical Journal 31 (1964), 389394.

[19] B. OpIC And A. Kufner, Hardy-type Inequalities, Pitman Research Notes in Mathematics Vol. 219, Longman Scientific \& Technical, Harlow (1990).

[20] J. A. Oguntuase And L.-E. Persson, Time scales Hardy-type inequalities via superquadracity, Annals of Functional Analysis 5 (2) (2014), 61-73.

[21] U. M. ÖZKAN AND H. YILDIRIM, Hardy-Knopp-type inequalities on time scales, Dynamic Systems and Applications 17 (3-4) (2008), 477-486.

[22] U. M. ÖZKAN AND H. YILDIRIM, Time scale Hardy-Knopp type integral inequalities, Communications in Mathematical Analysis 6 (1) (2009), 36-41.

[23] B. G. PAChPATte, A note on Copson's inequality involving series of positive terms, Tamkang Journal of Mathematics 21 (1) (1990), 13-19.

[24] P. ŘEHÁK, Hardy inequality on time scales and its application to half-linear dynamic equations, Journal of Inequalities and Applications 5 (2005), 495-507.

[25] S. H. SAKER, Hardy-Leindler type inequalities on time scales, Applied Mathematics \& Information Sciences 8 (6) (2014), 2975-2981.

[26] S. H. SAKER AND J. GRAEF, A New class of dynamic inequalities of Hardy's type on time scales, Dynamic Systems and Applications 23 (2014), 83-93.

[27] S. H. SAKer And D. O'Regan, Hardy and Littlewood inequalities on time scales, Bulletin of Malaysian Mathematical Science Society 39 (2016), 527-543.

[28] S. H. SAKER, D. O'REgAn AND R. P. AgaRWAL, Dynamic inequalities of Hardy and Copson types on time scales, Analysis: International Mathematical Journal of Analysis and its Applications 34 (3-4) (2014), 391-402.

[29] S. H. Saker, D. O'Regan And R. P. Agarwal, Generalized Hardy, Copson, Leindler and Bennett inequalities on time scales, Mathematische Nachrichten 287 (5-6) (2014), 687-698.

[30] S. H. Saker, D. O'Regan And R. P. Agarwal, Littlewood and Bennett Inequalities on time scales, Mediterranean Journal of Mathematics 8 (2014), 1-15.

[31] S. H. Saker, D. O'Regan And R. P. Agarwal, Some dynamic inequalities of Hardy's type on time scales, Mathematical Inequalities and Applications 17 (3) (2014), 1183-1199.

[32] S. H. Saker, R. R. Mahmoud and A. Peterson, Weighted Hardy-type inequalities on time scales with applications, Mediterranean Journal of Mathematics 13 (2016), 585-606.

[33] W. T. Sulaiman, Some Hardy type integral inequalities, Applied Mathematics Letters 25 (3) (2012), $520-525$.

[34] G.-Sh. YANG AND D.-Y. HwANG, Generalizations of some reverse integral inequalities, Journal of Mathematical Analysis and Applications 233 (1999), 193-204. 